\title{
Cross-sectional study of alteration of phantom limb pain with visceral stimulation in military personnel with amputation
}

\author{
Michael Rafferty, MRCS; ${ }^{*}$ Thomas M. Bennett Britton, MRCGP; $^{1}$ Benjamin T. Drew, MCSP; ${ }^{2}$ Rhodri D. Phillip, \\ FRCP $^{1}$ \\ ${ }^{1}$ Defence Medical Rehabilitation Centre Headley Court, Headley, Epsom, Surrey, United Kingdom; ${ }^{2}$ Musculoskeletal \\ Physiotherapy Services, Friarage Hospital, South Tees Hospitals National Health Service Foundation Trust, \\ Northallerton, North Yorkshire, United Kingdom
}

\begin{abstract}
While phantom limb pain is a well-recognized phenomenon, clinical experience has suggested that the augmentation of phantom limb pain with visceral stimulation is an issue for many military personnel with amputation (visceral stimulation being the sensation of the bowel or bladder either filling or evacuating). However, the prevalence of this phenomenon is not known. The aim of this study was to investigate the prevalence of the alteration in phantom limb pain and the effect that visceral stimulation has on phantom limb pain intensity. A crosssectional study of 75 military personnel who have lost one or both lower limbs completed a questionnaire to assess the prevalence of the alteration of phantom limb pain with visceral stimulation. Included in the questionnaire was a pain visual analog scale (VAS) graded from 0 to 10 . Patients recorded the presence and intensity of phantom limb pain. They also recorded whether and how this pain altered with a need to micturate or micturition, and/or a need to defecate or defecation, again using a pain VAS. Time since amputation, level of amputation, and medications were also recorded. Patients reported a phantom limb pain prevalence of $85 \%$ with a mean VAS of 3.6. In all, $56 \%$ of patients reported a change in the severity of phantom limb pain with visceral stimuli. The mean increase in VAS for visceral stimulation was $2.5+/-1.6$ for bladder stimulation and $2.9+/-2.0$ for bowel stimulation. Of the patients questioned, 65\% reported an improvement in symptoms over time. VAS scores were highest in the subgroup less than 6 mo postamputation. An increase in phantom limb pain with visceral stimulation is a common problem for military personnel with amputation.
\end{abstract}

Key words: amputation, bladder function, bowel function, defecation, micturition, military, phantom limb, phantom pain, phantom sensation, pain.

\section{INTRODUCTION}

Phantom limb pain is pain perceived in a region of the body that is no longer present. It occurs in 50 to 80 percent of all people with amputation [1]. Descriptions of phantom limb pain by patients are frequently referred to as knifelike, burning, sticking, throbbing, or shocking sensations [2]. The pain is often episodic in nature and of variable duration [3].

The number of military personnel with amputation in the United Kingdom has risen markedly as a result of the recent conflicts in Iraq and Afghanistan. This is due to the pattern of injuries caused by improvised explosive devices and improvements in trauma care that have resulted in a greater survival rate [4].

While phantom limb pain is a well-recognized phenomenon [5], clinical experience has suggested that the augmentation of phantom limb pain with visceral stimulation is an issue for many military personnel with amputation (visceral

Abbreviations: $\mathrm{AKA}=$ above-knee amputation, $\mathrm{BKA}=$ below-knee amputation, DMRC = Defence Medical Rehabilitation Centre, MODREC = Ministry of Defence Research Ethics Committee, VAS = visual analog scale.

*Address all correspondence to Michael Rafferty, MRCS; Defence Medical Rehabilitation Centre Headley Court, Headley, Epsom, Surrey, KT18 6JN; 01372-378271.

Email: rafferty83@gmail.com

http://dx.doi.org/10.1682/JRRD.2014.04.0114 
stimulation being the sensation of the bowel or bladder either filling or evacuating). However, the prevalence of this phenomenon is not known.

The aim of this study was to investigate the prevalence of the alteration in phantom limb sensation with visceral stimulation in military personnel with amputation and the effect that visceral stimulation has on phantom limb pain intensity.

\section{METHODS}

A questionnaire was designed to assess the severity of phantom limb pain and how it altered from the patient's baseline with visceral stimulation using a pain visual analog scale (VAS), which was graded from 0 (no pain) to 10 (most severe pain imaginable). The patient group was military inpatients at Defence Medical Rehabilitation Centre (DMRC) Headley Court who had undergone amputations, secondary to traumatic injury, of one or both of their lower limbs. This was a cross-sectional study, including all patients admitted to DMRC Headley Court over a period of 2 mo. Patients were offered the questionnaire during the hospital admission assessment by the admitting doctor.
All patients were treated by the same multidisciplinary rehabilitation team. This included regular reviews by pain specialists as well as extensive postamputation counseling. Each patient was started on an initial postoperative analgesia pathway of opiate analgesia as well as being loaded with pregabalin. Medication dosage was titrated to patient response, and further amendments to medications were undertaken if required (Figure 1).

Occupational therapists were involved in the treatment of all patients with the use of various therapies. A Graded Motor Imagery treatment plan consisting of a three-stage synaptic exercise process was used. This involved left/right discrimination, imagined movements, and mirror therapy with active range-of-motion exercises for $1 \mathrm{~h}$ a day for a minimum of $6 \mathrm{wk}$.

Patients recorded the presence and intensity of phantom limb pain at rest using the pain VAS. They also recorded whether and how this pain altered with a need to micturate or micturition, and/or a need to defecate or defecation, again using a pain VAS. Time since amputation, level of amputation, and medications used were also recorded. Patients were asked whether any of the medications or any other treatments had helped with this pain, whether the pain had improved over time, and to describe the pain in their own words.

\section{Pregabalin: start at $75 \mathrm{mg}$ twice a day, review every 3 days, and increase to maximum of $300 \mathrm{mg}$ twice a day. Therapeutic dose is $150 \mathrm{mg}-600 \mathrm{mg}$.}

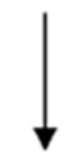
Long acting opiates (Morphine sulphate $10 \mathrm{mg}$ twice a day) + breakthrough pain (Oramorph
$5-10 \mathrm{mg}$ ) or Tramadol (50-100mg)

Amitriptyline: start at $10 \mathrm{mg} /$ nocte; review every two days \& titrate to maximum of $75 \mathrm{mg} /$ day

Treatment resistant consider adding: Tapentadol or Duloxetine (SNRI)

\section{Figure 1.}

Medication dosage procedure. SNRI = serotonin-norepinephrine reuptake inhibitors. 
Ethical approval was granted for this study by the Ministry of Defence Research Ethics Committee (MODREC).

\section{RESULTS}

All 75 patients approached completed the questionnaire. Their average age was $26.3 \mathrm{yr}$ (range 18-42 yr, standard deviation 5.2). There were 74 male patients and 1 female patient.

The presence of phantom limb pain at baseline was reported in 64 of 75 (85\%) of cases. The mean VAS in these 64 cases was $3.6 \pm 2.1$.

An alteration of phantom limb pain following visceral stimulation was reported by 42 of 75 (56\%) patients. In all, 39 of 75 (52\%) found an increase in pain with bladder stimulation, and 27 of 75 (36\%) with bowel stimulation. Twenty-four (32\%) patients reported an increase in phantom limb pain with both bladder and bowel stimulation. The mean increase in VAS for visceral stimulation was $2.5 \pm 1.6$ for bladder stimulation and $2.9 \pm 2.0$ for bowel stimulation (Tables 1-2). For a significant minority, there were much higher increases in VAS with visceral stimulation, with six patients having an increase in VAS of 5 or more. All patients who reported an increase in phantom limb pain with visceral stimulation had some degree of phantom limb pain at baseline.

Overall, of the 42 patients with an increase of phantom limb pain with visceral stimulation, 27 (65\%) patients

Table 1.

Mean phantom limb pain in all cohorts.

\begin{tabular}{lcc}
\hline \multicolumn{1}{c}{ Situation } & $\boldsymbol{n ~ ( \% )}$ & VAS Score \\
\hline At Rest & $42(56)$ & $2.4 \pm 2.1$ \\
Bladder Stimulation & $39(52)$ & $2.5 \pm 1.6$ \\
Bowel Stimulation & $27(36)$ & $2.9 \pm 2.0$ \\
Both & $24(32)$ & $2.6 \pm 2.0$ \\
\hline VAS = visual analog scale. & \\
\hline \hline
\end{tabular}

Table 2.

Amputation status visual analog scale (VAS) score.

\begin{tabular}{lc}
\hline \multicolumn{1}{c}{ Amputation Type } & VAS Score \\
\hline Single & $3.2 \pm 2.4$ \\
Double & $3.8 \pm 2.6$ \\
Triple & $2.3 \pm 2.4$ \\
Below-Knee & $2.3 \pm 2.6$ \\
Above-Knee & $2.9 \pm 2.1$ \\
\hline \hline
\end{tabular}

reported that there had been a reduction in their symptoms since the initial injury. In addition, VAS scores were highest in those patients who were less than 6 mo since amputation, with a baseline phantom pain mean of $4.2 \pm 2.3$, increasing to $5.9 \pm 2.5$ with bladder stimulation and $5.6 \pm$ 2.6 with bowel. In comparison, the over 24 mo group VAS score was $2.1 \pm 2.0$ at rest, increasing to $3.4 \pm 2.9$ with bladder and $3.0 \pm 3.2$ with bowel stimulation (Figure 2). There was a statistically significant difference between the time since amputation groups with an increase in VAS scores with visceral stimulation $(p=0.03)$.

Our study only included one female patient with a phantom limb VAS pain score of 7 at rest and no alteration of phantom limb pain with visceral stimulation.

For patients with phantom limb pain, 27 of 64 (42\%) reported that their symptoms improved with medication, with a mean VAS of $3.1 \pm 2.1$. Of the patients with worsening of phantom limb pain with visceral stimulation, 20 of 42 (48\%) reported an improvement of these symptoms with neuropathic medication. Other techniques recorded that eased the pain were massage, relaxation techniques, mirror therapy, and tapping or shaking the residual limb (Table 3).

There were 32 single amputations, 37 double amputations, and 7 triple amputations included. The mean VAS score at rest for those with a single amputation was $2.8 \pm 2.2$, for double amputation $2.7 \pm 1.8$, and for triple amputation $2.0 \pm 2.0$. There was no statistical difference between the groups ( $p=0.69$ ).

The mean VAS score increase from baseline with visceral stimulation for those with a single amputation was $3.2 \pm 2.4$, for double amputation $3.8 \pm 2.6$, and for triple amputation $2.3 \pm 2.4$ with no statistical difference $(p=$ 0.29 ) between the groups.

There were 30 below-knee amputations (BKAs) and 36 above-knee amputations (AKAs), with 9 people with bilateral amputation having a combination of above- and below-knee amputations. The mean VAS from BKA was $2.3 \pm 2.6$, for AKA $2.9 \pm 2.1$, and for bilateral mixedlevel amputations $3.1 \pm 3.8$. The level of amputation had no statistically significant difference in VAS scores $(p=$ 0.69).

Of the 75 patients participating in the study, 60 were under the age of $30 \mathrm{yr}$ at the time of amputation, with an average age in this group of $24.4 \pm 3.3 \mathrm{yr}$. The remaining 15 patients were over the age of $30 \mathrm{yr}$ at the time of amputation, with a mean age of $34.8 \pm 3.5 \mathrm{yr}$. 


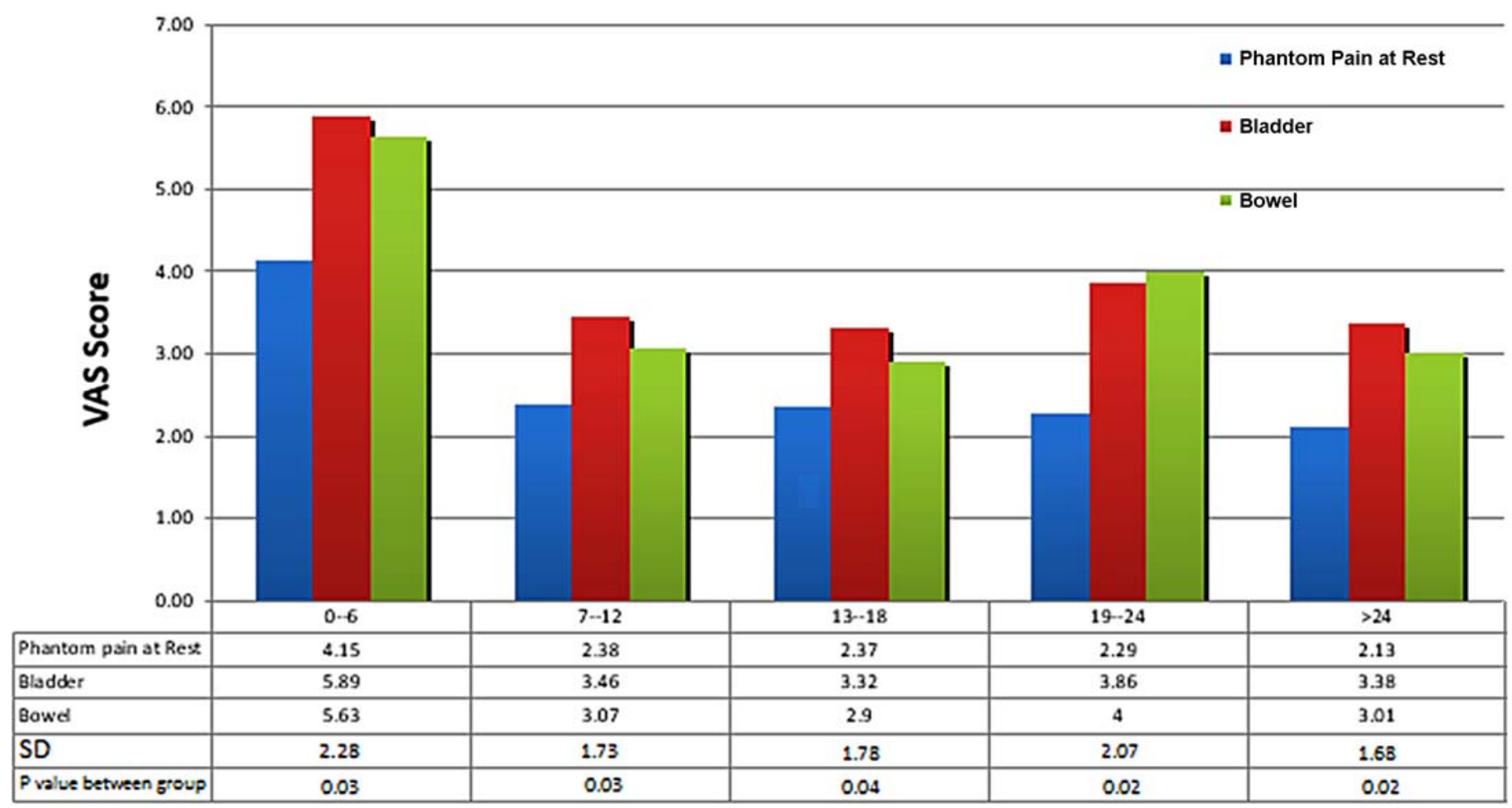

\section{Month Group}

Figure 2.

Visual analog scale (VAS) score: month groups. SD = standard deviation.

Table 3.

Treatment of phantom limb pain patient-reported effectiveness.

\begin{tabular}{lcc}
\hline \multicolumn{1}{c}{ Treatment } & Improvement \% & No Change \% \\
\hline Pharmacological & 28 & 71 \\
Pregabalin & 32 & 68 \\
Morphine Sulphate & 14 & 86 \\
Tramadol & 16 & 84 \\
Oramorph & 24 & 76 \\
Amitriptyline & 42 & 58 \\
Overall & & \\
Nonpharmacological & 36 & 64 \\
Massage Therapy & 42 & 58 \\
Compression Sock & 14 & 86 \\
Mirror Therapy & 48 & 52 \\
Distraction Therapy & 38 & 62 \\
Overall &
\end{tabular}

Of the 15 patients over $30 \mathrm{yr}$ old at injury, 9 (60\%) reported phantom limb pain and 6 were pain free. The mean VAS was $2.5 \pm 2.6$. The remaining 60 patients were under the age of $30 \mathrm{yr}$ at the time of amputation. Of this group, 55 (92\%) reported phantom limb pain with a VAS $3.1 \pm 2.3$ with a $p$-value of 0.14 between the two age groups baseline VAS.

The mean increase in VAS in the under $30 \mathrm{yr}$ group was $3.2 \pm 2.6$ compared with a VAS of $3.4 \pm 2.2$ with a $p$ value of 0.34 between the two groups.

There was no statistically significant difference between VAS scores at rest and with visceral stimulation between the two age groups.

The under $30 \mathrm{yr}$ age group mean time from amputation to time of the study was $13.2 \pm 10.2 \mathrm{mo}$, compared with the over $30 \mathrm{yr}$ age group that had an average time from amputation of $20.1 \pm 30.0 \mathrm{mo}$.

Additional comments from participants describing the pain alteration with visceral function include "a fizzing or burning pain when peeing," "like a hot poker being shoved on my limbs when I open my bowels," and "shooting pains down my (amputated) leg and calf which throbs when I need to pee.” 


\section{DISCUSSION}

This study found the prevalence of increase of phantom limb pain with visceral stimulation was 56 percent (42 of 75) among military inpatients with amputation at DMRC Headley Court, with variable increases in pain intensity. Our findings also suggest that phantom limb pain and its alteration with visceral stimulation improves with time from injury.

There are limitations to this study. This was a crosssectional study of inpatients being admitted to DMRC Headley Court over a period of 2 mo who had experienced amputations at various time points from less than 6 mo to over 24 mo previously and thus did not follow patients from the point of injury, and this is a potential source of bias because those patients returning to the rehabilitation center may not be fully representative of all people with traumatic amputation. In addition, in terms of treatment, military medical policy following amputation is to use relatively high doses of neuropathic and opiate medication in the acute stage and then to wean down the patients as tolerated as their rehabilitation progresses. This is a very subjective process that will differ in pace and success from patient to patient, and so the participants in this study at the time of assessment were not on the same pain medications; however, all patients were seen by the same initial pain management team and started on the same analgesia pathway.

In addition, pain scoring was simply recorded using a VAS grading system and did not use any validated quality of life outcome measures. The interaction between phantom pain and patient-reported quality of life outcome data would have further advanced this study.

There was no statistically significant difference found in VAS scores between age groups, and with only one female included in the study no statistically significant conclusions can be made.

Although the population in our study represents a young, predominately male population of soldiers at a previous high level of physical fitness, we believe that our results can be applied to the civilian population with traumatic amputations. Our study group was predominately people with lower-limb amputation with no isolated upper-limb amputation, but included seven people with triple amputations who had no significant difference in VAS scores compared to just people with lower-limb amputation.
There have been reports in the literature of an increase in phantom limb pain with visceral function previously, although this phenomenon is not widely recognized and has not previously been reported in military personnel with amputation.

An increase in phantom limb pain with urinary flow was first described in a letter to the editor of the Journal of the American Medical Association in 1971 [6], and a case report in 2001 found an increase in phantom limb pain with micturition in a patient with a left AKA [7].

In 2010, a case series in Leeds estimated the prevalence of alteration of phantom limb pain with visceral movement as about 10 percent, with 5 out of 50 patients describing it [8]. While the article did not report the demographics of the patients studied, the median age of the five patients with symptoms was $56 \mathrm{yr}$, with a range of 44 to $69 \mathrm{yr}$. Two of these had had amputations for ischemia and the other three for trauma. Therefore, the case series describes a very different patient group from those in this article, where all the patients had amputations secondary to trauma, with an average age of $26 \mathrm{yr}$, and the prevalence of alteration of phantom limb pain with visceral movement was 56 percent. Whether the demographics of the patients or the etiology of their amputations has any influence on the prevalence of the symptoms is not known, but they are more common in our patient group.

The pathophysiological mechanisms behind the existence of phantom limb pain are not fully understood, let alone the reasons why some patients experience worsening of their pain with visceral stimulation. A number of theories have been proposed to explain these phenomena.

The first of these is "sympathetic-sensory coupling." Peripherally, surface blood flow to the residual limb will be altered as a direct result of the injury, but the initial injury will also cause a loss of sympathetic activity, leading to vasodilatation. Nerve laceration is thought to trigger a massive sprouting of sympathetic fibers at the injury site as a result [9]. This is also associated with an upregulation of alpha-adrenergic receptors in the primary afferent neurons, allowing for the vessels to be more responsive to changes in sympathetic tone [9]. It is suggested that as the peripheral afferent neurons and sympathetic nerves grow back, "cross-talk" occurs between them [10]. Therefore, alterations that occur in sympathetic tone during visceral function may mediate an exaggerated and painful response in the phantom limb.

Cortical reorganization of the amputation zone within the somatosensory and motor cortex is known to occur 
postamputation, and it has been suggested as being responsible for the production of phantom limb sensation [11]. Body image is maintained by tactile, proprioceptive, and visual input. These stimuli are profoundly altered following amputation, with this distortion often resulting in pain [12]. Reorganization of the amputation zone within the somatosensory and motor cortex occurs, and other representative areas in the cortex expand and encroach upon the amputated zone [11]. Mirror therapy has been shown to reduce pain in phantom limb pain patients, and its mechanism of action is thought to be by slowing or reversing this process [13]. It is possible that as cortical reorganization takes place, the regulatory pathways controlling the pelvic organs that exist at higher levels may become linked with those that formerly supplied the limbs, thereby providing a mechanism for phantom limb pain to occur with visceral stimulation [8].

A further theory is that of spinal sensitization. At the spinal level, amputation induces a state of deafferentation silence, or at the very least disorganization, with abnormal discharges from neuromas and the dorsal root ganglia that have been disrupted [14]. Both visceral afferents from the gut and somatic nerves have cell bodies in the dorsal root ganglia and enter the dorsal horn of the spinal cord [15]. It is possible that the state induced by the amputation results in changes in the dorsal horn neuron receptive fields at the spinal level [14]. Nearby neurons that include other anatomical or functional areas may become incorporated into the area corresponding to the amputated zone [16] so that visceral sensation results in painful stimulation felt in the area of amputation.

Finally, an increase in muscular tone may also be responsible for the pain. Relief of phantom limb pain has been achieved with muscle relaxation techniques that reduce tensing or cramping of the muscles in the amputated limb [17]. Therefore, it is possible that raised intraabdominal pressure resulting from bowel or bladder straining also increases the tone in the muscles of the amputated limb. While increased muscular tone may have a contributory nature to the increased phantom limb pain with visceral stimulation, given the description of the pain's character and nature, it is unlikely to be the full explanation.

\section{CONCLUSIONS}

An increase in phantom limb pain with visceral stimulation is a common problem for military personnel with amputation.

\section{ACKNOWLEDGMENTS}

\section{Author Contributions:}

Conception and design of research: T. M. Bennett Britton, R. D. Phillip. Acquisition of data: M. Rafferty, T. M. Bennett Britton.

Analysis and interpretation of data: M. Rafferty, T. M. Bennett Britton, B. T. Drew, R. D. Phillip.

Drafting and critical revision of article: M. Rafferty,

T. M. Bennett Britton, B. T. Drew, R. D. Phillip.

Approval of final submitted version: M. Rafferty, T. M. Bennett Britton, B. T. Drew, R. D. Phillip.

Financial Disclosures: The authors have declared that no competing interests exist.

Funding/Support: This material was unfunded at the time of manuscript preparation.

Institutional Review: MODREC was consulted and approved the study.

Participant Follow-Up: The authors plan to provide copies and an explanation of the study outcome to each participant.

\section{REFERENCES}

1. Jensen TS, Nikolajsen L. Phantom pain and other phenomena after amputation. In: Wall PD, Melzack R, editors. Textbook of pain. 4th ed. Edinburgh (UK): Churchill Livingstone; 1999. p. 799-814.

2. Jensen TS, Krebs B, Nielsen J, Rasmussen P. Immediate and long-term phantom limb pain in amputees: Incidence, clinical characteristics and relationship to pre-amputation limb pain. Pain. 1985;21(3):267-78. [PMID:3991231] http://dx.doi.org/10.1016/0304-3959(85)90090-9

3. Weeks SR, Anderson-Barnes VC, Tsao JW. Phantom limb pain: Theories and therapies. Neurologist. 2010;16(5):277-86. [PMID:20827116] http://dx.doi.org/10.1097/NRL.0b013e3181edf128

4. Brown KV, Guthrie HC, Ramasamy A, Kendrew JM, Clasper J. Modern military surgery: Lessons from Iraq and Afghanistan. J Bone Joint Surg Br. 2012;94(4):536-43. [PMID:22434472] http://dx.doi.org/10.1302/0301-620X.94B4.28602

5. Ephraim PL, Wegener ST, MacKenzie EJ, Dillingham TR, Pezzin LE. Phantom pain, residual limb pain, and back pain in amputees: Results of a national survey. Arch Phys Med Rehabil. 2005;86(10):1910-19. [PMID:16213230] http://dx.doi.org/10.1016/j.apmr.2005.03.031

6. Maloney PK Jr. Phantom sensation with urinary flow. JAMA. 1971;218(7):1052. [PMID:5171038] http://dx.doi.org/10.1001/jama.1971.03190200082031

7. Humphreys S, Campbell W. Augmentation of phantom limb pain by normal visceral function. Ulster Med J. 2001; 70(2):142-44. [PMID:11795765] 
8. Sivan M, Stoppard E, Kirker S. Alteration in phantom pain and sensation with visceral movement. PM R. 2010;2(6): 576-78. [PMID:20630446] http://dx.doi.org/10.1016/j.pmrj.2010.02.005

9. Devor M. The pathophysiology of damaged peripheral nerves. In: Wall PD, Melzack R, editors. Textbook of pain. 3rd ed. Edinburgh (UK): Churchill Livingstone; 1994. p. 79-100.

10. Flor H, Birbaumer N, Sherman RA. Phantom limb pain. Pain Clinical Updates. 2000;8(3).

11. Grüsser SM, Winter C, Mühlnickel W, Denke C, Karl A, Villringer K, Flor $\mathrm{H}$. The relationship of perceptual phenomena and cortical reorganization in upper extremity amputees. Neuroscience. 2001;102(2):263-72.

[PMID:11166112] http://dx.doi.org/10.1016/S0306-4522(00)00491-7

12. Lotze M, Moseley GL. Role of distorted body image in pain. Curr Rheumatol Rep. 2007;9(6):488-96. [PMID:18177603] http://dx.doi.org/10.1007/s11926-007-0079-x

13. Meyer P, Matthes C, Kusche KE, Maurer K. Imaginative resonance training (IRT) achieves elimination of amputees' phantom pain (PLP) coupled with a spontaneous in-depth proprioception of a restored limb as a marker for permanence and supported by pre-post functional magnetic resonance imaging (fMRI). Psychiatry Res. 2012;202(2):175-79. [PMID:22748628] http://dx.doi.org/10.1016/j.pscychresns.2011.08.012

14. Price DD, Mao J, Mayer DJ. Central consequences of persistent pain states. Proceedings of the 8th World Congress on Pain, Progress in Pain Research and Management. Vol 8. Seattle (WA): ISAP Press; 1997. p. 155-84.
15. Gifford L, Thacker M. A clinical overview of the autonomic nervous system, the supply to the gut and mindbody pathways. In: Gifford L, editor. Physiotherapy pain association. Topical issues in pain 3. Falmouth (ME): CNS Press; 2002. p. 21-51.

16. Doubell TP, Mannion RJ, Woolf CJ. The dorsal horn: State dependent sensory processing, plasticity and generation of pain. In: Wall PD, Melzack R, editors. Textbook of pain. 4th ed. Edinburgh (UK): Churchill Livingstone; 1999. p. 165-81.

17. Sherman RA, Gall N, Gormly J. Treatment of phantom limb pain with muscular relaxation training to disrupt the pain—anxiety—tension cycle. Pain. 1979;6(1):47-55. [PMID:370738] http://dx.doi.org/10.1016/0304-3959(79)90139-8

Submitted for publication April 25, 2014. Accepted in revised form March 25, 2015.

This article and any supplementary material should be cited as:

Rafferty M, Bennett Britton TM, Drew BT, Phillip RD. Cross-sectional study of alteration of phantom limb pain with visceral stimulation in military personnel with amputation. J Rehabil Res Dev. 2015;52(4):441-48.

http://dx.doi.org/10.1682/JRRD.2014.04.0114

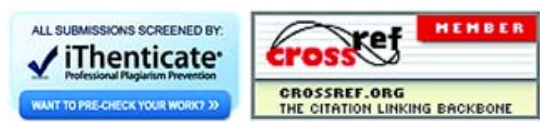


